\title{
PENGARUH TERAPI SENAM ERGONOMIK TERHADAP PENURUNAN TEKANAN DARAH PADA LANSIA PENDERITA HIPERTENSI
}

\author{
Jumari, Windi Indriani Putri \\ Program Studi Ilmu Keperawatan, Sekolah Tinggi Ilmu Kesehatan Indonesia Maju, Jl. Harapan \\ Lenteng Agung, Jakarta Selatan, 12630 Indonesia \\ Email : ns.jumari@gmail.com
}

\begin{abstract}
Abstrak
Hipertensi merupakan keadaan dimana seseorang mengalami peningkatan tekanan darah diatas normal yaitu sistolik lebih dari $140 \mathrm{mmHg}$ dan diastolik lebih dari $90 \mathrm{mmHg}$. Tujuan dari penelitian ini yaitu untuk mengetahui pengaruh terapi senam ergonomik terhadap penurunan tekanan darah pada lansia penderita hipertensi di Puskesmas Citapen, Ciawi, Bogor. Metode penelitian ini menggunakan penelitian kuantitatif dengan desain penelitian Pra eksperimental one group pretest-posttest yang hanya menggunakan kelompok intervensi dengan uji dependen (Paired T-test). Sampel yang digunakan dalam penelitian ini adalah 20 responden lansia yang mengalami hipertensi teknik pengambilan sampel dengan menggunakan total sampling. Hasil penelitian ini menunjukkan bahwa nilai rata-rata tekanan darah sistolik sebelum diberikan intervensi adalah $155 \mathrm{mmHg}$ dan sesudah diberikan intervensi adalah $140 \mathrm{mmHg}$ serta tekanan darah diastolik sebelum diberikan intervensi adalah $93 \mathrm{mmHg}$ dan sesudah diberikan intervensi adalah $86 \mathrm{mmHg}$. Adanya pengaruh terapi senam ergonomik terhadap penurunan tekanan darah sistolik dengan nilai rata-rata $15 \mathrm{mmHg}$ dengan standar deviasi 6, didapatkan nilai signifikasi $0.000(\mathrm{p}=<0.05)$ dan tekanan darah diastolik dengan nilai rata-rata $7 \mathrm{mmHg}$ degan standar deviasi 5 , didapatkan juga nilai signifikasi $0.000(\mathrm{p}=<0.05)$. Maka dapat disimpulkan bahwa adanya pengaruh terapi senam ergonomik terhadap penurunan tekanan darah pada lansia penderita hipertensi.
\end{abstract}

Kata kunci : senam ergonomik, tekanan darah, lansia.

\section{Abstract}

Hypertension is a condition when a person experiences elevated blood pressure up normal, which is systolic over $140 \mathrm{mmHg}$ and diastolic over $90 \mathrm{mmHg}$. The purpose of this research is to understand the effects of ergonomic exercise on a decline blood pressure on elderly people with hypertension at the Citapen Health Center, Ciawi, Bogor. These methods of research used quantitative research with a pre-experimental one group pretest-posttest research design that only used an intervention group with a dependent test (paired t-test). The samples used in this research were 20 elderly respondents who experienced hypertension sampling techniques using total sampling. The results of this research shows that the average value of systolic blood pressure before intervention is $155 \mathrm{mmHg}$ and after intervention is $140 \mathrm{mmHg}$ and while diastolic blood pressure before intervention is $93 \mathrm{mmHg}$ and after intervention is $86 \mathrm{mmHg}$. The effects of ergonomic exercise therapy before and after against an average drop in systolic blood pressure of $15 \mathrm{mmHg}$ to standard deviation of 6, it gaied signification value of $0.000(p=<0.05)$ and a diastolic blood pressure elevated to an average value of $7 \mathrm{mmHg}$ to standard deviation of 5 , also obtained a significance value of $0.000(p=<0.05)$. it concluded that the effects of ergonomic exercise on blood pressure in hypertension older people are affected.

Keywords : ergonomic exercise, blood pressure, elderly. 


\section{PENDAHULUAN}

Hipertensi merupakan masalah kesehatan global yang berakibat pada peningkatan angka kesakitan dan kematian serta beban biaya kesehatan yang tinggi (PDHI, 2019). Hipertensi merupakan keadaan dimana seseorang mengalami peningkatan tekanan darah diatas normal yang mengakibatkan angka kesakitan dan kematian paling tinggi di dunia. Tekanan darah dikatakan tinggi apabila terjadi peningkatan tenakan darah sistolik lebih dari $140 \mathrm{mmHg}$ dan diastolik lebih dari $90 \mathrm{mmHg}$. Hipertensi atau tekanan darah tinggi merupakan salah satu penyakit degeneratif yang paling banyak ditemukan dalam kalangan masyarakat (Suwanti et al., 2019).

Permasalahan penyakit degeneratif seperti hipertensi merupakan penyakit yang berkembang pada masyarakat dunia dari tahun ke tahunnya. Data World Health Organization (WHO) tahun 2011, menunjukkan 1 milyar orang didunia menderita hipertensi, 2/3 diantaranya berada di negara berkembang yang berpenghasilan rendah hingga sedang. Menurut data Sample Registration System (SRS) Indonesia tahun 2014, hipertensi dengan komplikasi (5,3\%) merupakan penyebab kematian nomor 5 (lima) setelah pada semua usia menyebabkan kematian sekitar 8 juta jiwa setiap tahunnya, penderita hipertensi yang tidak mendapat penanganan yang baik maka mengakibatkan komplikasi seperti stroke (51\%), penyakit jantung koroner (45\%), diabetes melitus, gagal ginjal serta kebutaan (Kemenkes RI, 2017). Data statistik menyatakan terdapat $24,7 \%$ penduduk Asia Tenggara dan 23,3\% penduduk Indonesia usia $\geq 18$ tahun mengalami hipertensi terjadi pada tahun 2014³. Pada tahun 2016 di Jawa Barat terdapat 790.382 jiwa pada kasus hipertensi atau sekitar 2,46\% pada penduduk usia $\geq 18$ tahun dari jumlah populasi yang diperiksa sebanyak
8.029.245 jiwa. Kejadian tertinggi di provinsi Jawa Barat adalah Kota Cirebon dengan $17,18 \%$ dan terendah di Kota Pangandaran dengan 0,05\%. Sedangkan, untuk wilayah Kota Bogor ditemukan sebanyak 1,49\% dan di Kabupaten Bogor sebanyak 0,34\% (PERNEFRI, 2019). Untuk Kecamatan Ciawi sendiri didapatkan data kejadian hipertensi yang dilakukan pada tahun 2015 sebesar 191 jiwa atau sekitar $100 \%$ dari jumlah yang telah memeriksakan kesehatannya(DinKes, 2016). Sedangkan, di wilayah kerja Puskesmas Citapen, Ciawi, Bogor pada tahun 2018 terdapat 76 orang yang terdiagnosa hipertensi dan mengalami peningkatan pada tahun 2019 menjadi 134 orang terdiagnosa hipertensi terhitung dari bulan Januari hingga September 2019.

Hipertensi dapat mengakibatkan suplai oksigen dan nutrisi dalam darah yang dibawa keseluruh tubuh akan terhambat. Hipertensi juga mempunyai gejala seperti sakit kepala dan jika parah merasa akan pingsan, merasa pendengaran berdengung dan penglihatan kabur. Hipertensi ini disebabkan oleh faktor terkontrol seperti, obesitas atau kegemukan, mengkonsumsi garam berlebih, merokok, mengkonsumsi alkohol dan stres sedangkan faktor tidak terkontrol seperti, keturunan atau genetik, jenis kelamin dan usia (Suwanti et al., 2019). Menurut data American Heart Asociation (AHA) pada tahun 2018, kejadian hipertensi meningkat seiring dengan pertambahan usia yang dimulai ketika seseorang berusia diatas 20 tahun dan puncaknya mencapai usia 75 tahun keatas (Dinkes Bogor, 2015). Angka kejadian tertinggi hipertensi didapatkan pada populasi lanjut usia, usia 45-54 tahun didapatkan data sebanyak $45,3 \%$, pada usia 55-64 tahun sebanyak 55,2\%, usia 65-74 tahun sebanyak $63,2 \%$ dan angka kejadian tertinggi pada usia $\geq 75$ tahun sebanyak 69,5\% (Nurfitri et al., 2019). 
Tingginya angka kejadian tersebut disebabkan oleh faktor bertambahnya usia karena semakin bertambah usia maka fungsi tubuh manusia semakin menurun (Riskesdas, 2018). Karena banyaknya perubahan yang terjadi pada lansia dan terjadi masalah kesehatan yang signifikan maka untuk mempertahankan kesehatan perlu upaya sebagai perawatan, pengobatan dan menerapkan hidup sehat seperti merubah pola dan gaya hidup dengan menurunkan berat badan untuk individu yang obesitas, mengurangi konsumsi garam, mengurangi stress berlebih dan aktivitas fisik (Perdana, 2014). Penanganan hipertensi atau penurunan tekanan darah tinggi dapat di berikan dengan penanganan farmakologi atau nonfarmakologi. Penanganan nonfarmakologi dapat diberikan dengan melakukan aktivitas fisik olahraga seperti senam. Senam yang dilakukan untuk menurunkan tekanan darah tinggi sudah banyak terapinya seperti, senam tera, yoga, senam kegel dan salah satunya senam ergonomik (Sandi, 2017). Senam ergonomik merupakan senam yang diilhami dari Gerakan shalat, memiliki fungsi autoregulasi karena shalat mengandung Gerakan dari hati, lisan dan Gerakan badan (Priyanti, 2016). Gerakan senam ergonomik disesuaikan dengan kaidah-kaidah penciptaan tuhan yang dialami dari Gerakan shalat. Sehingga memiliki arti bahwa senam ergonomik dapat langsung membuka, membersihkan dan mengaktifkan seluruh sistem dalam (Budisulystio, 2006). Gerakan senam ergonomik terdiri dari enam gerakan seperti, gerakan berdiri sempurna, lapang dada, tunduk syukur, duduk perkasa, duduk pembakaran dan berbaring pasrah. Dalam gerakan-gerakan tersebut yang dapat menurunkan tekanan darah adalah gerakan duduk perkasa karena gerakan ini dapat membuat otot dada dan sela iga menjadi kuat sehingga rongga dada lebih besar dan paru-paru berkembang dengan baik dan dapat menghisap oksigen lebih banyak dan menambah aliran dara ke tubuh bagian atas. Gerakan senam ergonomik ini dapat dilakukan secara rutin setiap hari atau dilakukan 2-3 kali dalam seminggu (Nurfitri et al., 2019).

\section{METODE PENELITIAN}

Metode penelitian ini adalah kuantitatif dengan desain penelitian Pra eksperimental one group pretest-posttest. dengan menggunakan uji paired t-test. Sampel yang digunakan dalam penelitian ini adalah 20 responden lansia yang mengalami hipertensi teknik pengambilan sampel dengan menggunakan total sampling

Penelitian ini menggunakan metode preeksperiment menggunakan rancangan pretest-posttest tanpa kelompok kontrol. Variabel bebas dalam penelitian ini adalah senam lansia dan variabel terikat yaitu tekanan darah pada lansia penderita hipertensi. Populasi dalam penelitian ini adalah semau lansia penderita hipertensi di di Puskesmas Citapen, Ciawi, Bogor yang berjumlah 33 orang lansia. Sampel yang digunakan dalam penelitian ini menggunakan purposive sampling sebanyak 20 orang lansia yang mengalami hipertensi inklusi penelitian, yaitu: penderita dengan Hipertensi ringan : 140$159 \mathrm{mmHg}$ 90-99 $\mathrm{mmHg}$ sampai Hipertensi sedang : 160-179 mmHg 100$109 \mathrm{mmHg}$, mempunyai usia diatas 39 tahun sampai dengan 60 tahun, tidak menggunakan obat penurun tekanan darah, sampel tidak dalam kategori gemuk (obesitas), dan sampel wanita tidak sedang menggunakan pil KB.

Penelitian ini menggunakan alat dan pengumpulan data ceklist, lembar observasi, pemeriksaan tekanan darah, pengukuran tekanan darah menggunakan Tensimeter digital OMRON HEM seri 8712 dan video senam ergonomik. Mengetahui rata-rata tekanan darah sebelum dan sesudah dilakukan senam 
ergonomik dengan menggunakan uji paired t-test. Perlakukan (treatment) diberikan secara teratur 3 kali dalam satu minggu selama 4 minggu atau 12 kali pertemuan

\section{HASIL PENELITIAN}

Tabel 1

Rata-rata tekanan darah sistolik dan diastolik sebelum diberikan intervensi senam ergonomik $(\mathrm{N}=\mathbf{2 0})$

\begin{tabular}{|c|c|c|c|}
\hline Variabel & Mean & $\begin{array}{c}\text { Std. } \\
\text { Deviasi }\end{array}$ & $\begin{array}{c}\text { Std. Error } \\
\text { Mean }\end{array}$ \\
\hline $\begin{array}{l}\text { Tekanan } \\
\text { darah } \\
\text { sistolik } \\
\text { sebelum } \\
\text { senam } \\
\text { ergonomik }\end{array}$ & 154.75 & 18.530 & 4.143 \\
\hline $\begin{array}{l}\text { Tekanan } \\
\text { darah } \\
\text { sistolik } \\
\text { sesudah } \\
\text { senam } \\
\text { ergonomik }\end{array}$ & 140.00 & 19.67 & 4.353 \\
\hline $\begin{array}{l}\text { Tekanan } \\
\text { darah } \\
\text { diastolik } \\
\text { sebelum } \\
\text { senam } \\
\text { ergonomik }\end{array}$ & 93.00 & 6.569 & 1.469 \\
\hline $\begin{array}{l}\text { Tekanan } \\
\text { darah } \\
\text { diastolik } \\
\text { sesudah } \\
\text { senam } \\
\text { ergonomik }\end{array}$ & 86.25 & 6.257 & 1.399 \\
\hline
\end{tabular}

Rata-rata tekanan darah sistolik sebelum diberikan intervensi senam ergonomik dapat dilihat pada tabel dan rata-rata tekanan darah diastolik sebelum diberikan intervensi senam ergonomik dapat dilihat pada tabel 1 menunjukkan bahwa rata-rata tekanan darah sistolik pada lansia penderita hipertensi sebelum diberikan intervensi senam ergonomik mendapatkan nilai mean 154,75 atau $155 \mathrm{mmHg}$ dengan standar deviasi 18,530 atau 19. dan kemudian diukur tekanan darah akhir untuk melihat adanya penurunan tekanan darah pada penderita hipertensi.

menunjukkan bahwa rata-rata tekanan darah diastolik pada lansia penderita hipertensi sebelum diberikan intervensi senam ergonomik mendapatkan nilai mean 93,00 atau $93 \mathrm{mmHg}$ dengan standar deviasi 6,569 atau 7.

\section{Rata-rata tekanan darah sistolik dan diastolik sesudah diberikan intervensi senam ergonomik}

Rata-rata tekanan darah sistolik sesudah diberikan intervensi senam ergonomik dapat dilihat pada tabel 1 dan rata-rata tekanan darah diastolik sesudah diberikan intervensi senam ergonomik menunjukkan bahwa ratarata tekanan darah sistolik pada lansia penderita hipertensi sesudah diberikan intervensi senam ergonomik mendapatkan nilai mean 140,0 atau $140 \mathrm{mmHg}$ dengan standar deviasi 19,467 atau 19.

Table diatas menunjukkan bahwa rata-rata tekanan darah diastolik pada lansia penderita hipertensi sesudah diberikan intervensi senam ergonomik mendapatkan nilai mean 86,25 atau $86 \mathrm{mmHg}$ dengan standar deviasi 6,275 atau 6.

\section{Pengaruh terapi senam ergonomik terhadap tekanan darah sistolik dan diastolik pada lansia penderita hipertensi di Puskesmas Citapen, Ciawi, Bogor}

Pengaruh terapi senam ergonomik terhadap penurunan tekanan darah sebelum dan sesudah diberikan intervensi senam ergonomik dapat dilihat pada tabel 2 dan tabel 3 
Tabel 2

Pengaruh terapi senam ergonomik sebelum dan sesudah diberikan intervensi senam ergonomik terhadap tekanan darah sistolik pada lansia penderita hipertensi $(n=20)$

\begin{tabular}{|c|c|c|c|c|c|c|c|c|}
\hline \multicolumn{6}{|c|}{ Paired Differences } & \multirow[t]{2}{*}{$\mathrm{T}$} & \multirow[t]{3}{*}{$\mathrm{df}$} & \multirow[t]{2}{*}{$\begin{array}{l}\text { Sig. (2- } \\
\text { tailed) }\end{array}$} \\
\hline & Mean & $\begin{array}{c}\text { Std. } \\
\text { Deviation }\end{array}$ & $\begin{array}{l}\text { Std. } \\
\text { Error } \\
\text { Mean }\end{array}$ & $\begin{array}{r}95 \% \mathrm{C} \\
\text { Intery } \\
\text { Diff }\end{array}$ & $\begin{array}{l}\text { fidence } \\
\text { of the } \\
\text { nce }\end{array}$ & & & \\
\hline & & & & Lower & Upper & & & \\
\hline $\begin{array}{c}\text { Tekanan darah sistolik } \\
\text { sebelum senam ergonomik - } \\
\text { tekanan darah sistolik sesudah } \\
\text { senam ergonomik }\end{array}$ & 14.750 & 6.172 & 1.380 & 11.861 & 17.639 & 10.688 & 19 & .000 \\
\hline
\end{tabular}

Tabel 2 menunjukkan bahwa adanya pengaruh senam ergonomik terhadap tekanan darah sistolik pada lansia penderita hipertensi. Terjadi penurunan rata-rata tekanan darah sistolik dengan rata-rata nilai tekanan darah sistolik sebelum dan sesudah diberikan intervensi senam ergonomik adalah 14,75 atau $15 \mathrm{mmHg}$ dengan standar deviasi 6,172 atau 6. Dari nilai $\mathrm{p}=0,000$ diketahui bahwa adanya pengaruh senam ergonomik terhadap tekanan darah sistolik.

Tabel 3

Pengaruh terapi senam ergonomik sebelum dan sesudah diberikan intervensi senam ergonomik terhadap tekanan darah diastolik pada lansia penderita hipertensi $(n=20)$

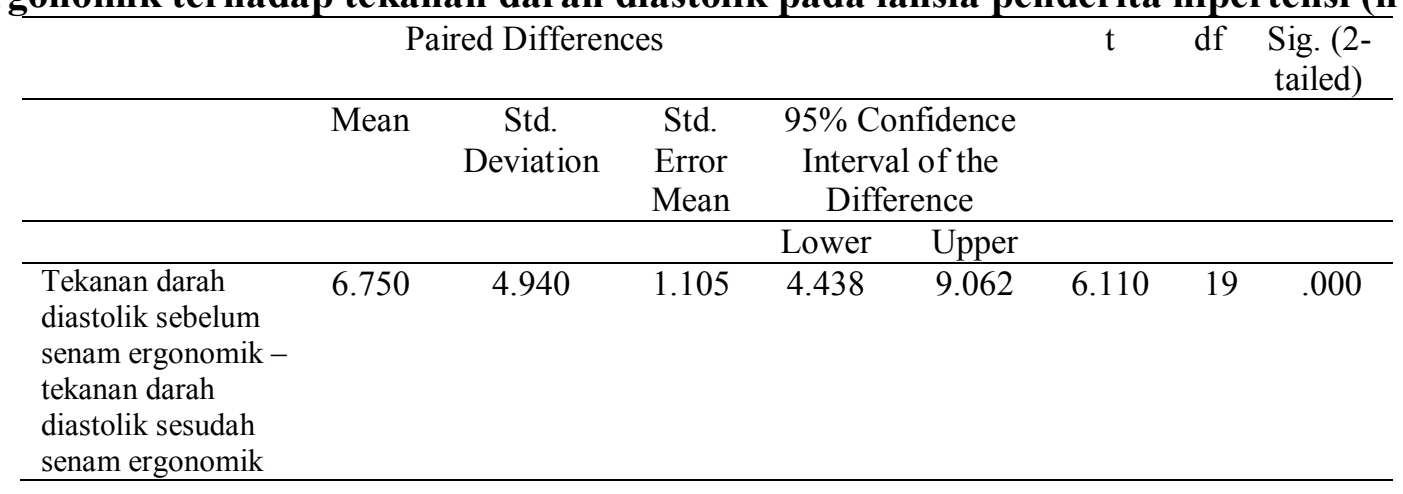

Tabel 3 menunjukkan bahwa adanya pengaruh senam ergonomik terhadap tekanan darah diastolik pada lansia penderita hipertensi. Terjadi penurunan rata-rata tekanan darah diastolik dengan rata-rata nilai tekanan darah diastolik sebelum dan sesudah

\section{PEMBAHASAN}

Pengaruh terapi senam ergonomik sebelum dan sesudah diberikan intervensi senam ergnomik terhadap tekanan darah sistolik dan diastolik pada lansia penderita hipertensi diberikan intervensi senam ergonomik adalah 6,75 atau $7 \mathrm{mmHg}$ dengan standar deviasi 4,94 atau 5. Dari nilai $\mathrm{p}=0,000(\mathrm{p}=<0.005)$ diketahui bahwa adanya pengaruh senam ergonomik terhadap tekanan darah diastolik.

Berdasarkan hasil output menunjukan bahwa adanya pengaruh terapi senam ergonomik sebelum dan sesudah terhadap penurunan tekanan darah sistolik dengan nilai rata-rata $15 \mathrm{mmHg}$ dengan standar deviasi 6, idapatkan nilai signifikasi $0.000(p=<0.05)$ dan tekanan darah diastolik dengan nilai rata-rata $7 \mathrm{mmHg}$ 
degan standar deviasi 5, didapatkan juga nilai signifikasi $0.000 \quad(p=<0.05)$. maka dapat dikatakan adanya pengaruh yang signifikan antara variabel terapi senam ergonomik terhadap penurunan tekanan darah.

Penelitian lain juga mengungkapkan bahwa dari 27 lansia yang tekanan darahnya turun $<140 / 90 \mathrm{mmHg}$ terdapat 19 responden (70,5\%) menurutnya, keadaan tersebut dikarenakan bertambahnya usia berpengaruh kepada penebalan pembuluh darah dan menyebabkan penyempitan pembuluh darah yang berpengaruh pada aliran darah dalam tubuh, jika ditambah dengan kurangnya aktivitas fisik maka dapat mengakibatkan kefatakan pada pembuluh darah dan mengakibatkan komplikasi (Wratsongko, 2015).

Oleh senam ergonomik, seseorang akan merasa lebih rileks dikarenakan gerakangerakan yang didalamnya. Yang pertama yaitu gerakan pembuka dengan posisi berdiri

\section{KETERBATASAN PENELITIAN}

Tidak adanya matras, sehingga responden kesulitan dalam beberapa gerakan dan sedikit merada sakit di kakinya karena telalu lama menahan gerakannya, perlu bantuan tim untuk dapat mengatur dan membantu responden dalam beberapa gerakan dan pada saat pemeriksaan tekanan darah terjadi kurang kondusif karena responden ingin saling mendahului dan tidak mengikuti antrian.

\section{KESIMPULAN}

Rata-rata tekanan darah sistolik sebelum diberikan intervensi senam ergonomik dengan 20 responden didapatkan nilai rata-rata 155 mmHg dengan standar deviasi 19 dan ratarata tekanan darah diastolik $93 \mathrm{mmHg}$ dengan standar deviasi 7. Rata-rata tekanan darah sistolik sesudah diberikan intervensi senam ergonomik didapatkan nilai rata-rata $140 \mathrm{mmHg}$ dengan standar deviasi 19 dan rata-rata tekanan darah diastolik $86 \mathrm{mmHg}$ sempurna, gerakan ini menjadikan kondisi yang lebih rileks. Gerakan kedua yaitu gerakan lapang dada agar lebih mengaktifkan sistem organ tubuh. Gerakan ketiga yaitu gerakan tunduk syukur sebagai pemasok oksigen yang lebih banyak ke otak. Gerakan ke empat dan kelima adalah gerakan duduk perkasadan duduk pembakaran, gerakan ini akan terjadi proses pembakaran yang akan meningkatkan daya tahan tubuh dengan posisi kepala yang sujud akan membuat otot dada dan sela iga menjadi kuat dan membuat rongga dada menjadi lebih luas dan paru-paru akan berkembang lebih baik dan dapat menghirup oksigen lebih banyak (Budisulystio, 2006). Sehingga peneliti beramsumsi bahwa dengan melakukan aktivitas fisik seperti berolahraga senam ergonomik ini maka aliran darah yang memabawa oksigen masuk ke otak akan lancar dan tidak dapat menyebabkan terjadinya hambatan sehingga menyebabkan penyumbatan pembuluh darah.

dengan standar deviasi 6. Adanya pengaruh terapi senam ergonomik terhadap penurunan tekanan darah pada lansia penderita hipertensi di Puskesmas Citapen, Ciawi, Bogor, dengan hasil $\mathrm{p}=0.000$.

\section{SARAN}

\section{Institusi pemerintahan (Puskesmas Citapen, Ciawi, Bogor)}

Diharapkan dengan adanya tambahan senam ergonomik ini dapat menjadi bagian dari senam prolanis karena gerakannya yang simpel dan lansia juga dapat melakukannya. Diharapkan senam prolanis yang rutin diadakan di Puskesmas dapat dikelompokkan sesuai dengan usia dan penyakitnya agar senam lebih terarah dan sesuai dengan sasarannya, serta senam tersebut tidak hanya dilakukan di Puskesmas tetapi dapat dilakukan secara rutin di tempat lain contohnya di posyandu lansia agar lansia yang tidak aktif atau jarak yang jauh dapat mengikutinya di tempatnya yang lebih dekat. 


\section{Institusi Pendidikan}

Sebagai bahan pembelajaran mengenai cara mengobati tekanan darah selain dengan cara farmakologi yaitu dengan non farmakologi seperti senam ergonomik ini. Hasil penelitian ini diharapkan dapat menambah wawasan kepada ilmu kesehatan terlebih dalam ilmu keperawatan untuk salah satu intervensi menurunkan tekanan darah yang tinggiPeneliti selanjutnya

\section{DAFTAR PUSTAKA}

Budisulystio, T. (2006). 205 Resep Pencegahan \& Penyembuhan Penyakit Dengan Gerakan Shalat. Qultum Media, 182.

Dinkes Bogor. (2015). Resume Profil Kesehatan kabupaten Bogor.

DinKes, J. B. (2016). Profil Kesehatan Provinsi Jawa Barat. Dinas Kesehatan Jawa Barat, 1-138.

Kemenkes RI. (2017). Analisis Lansia di Indonesia. Pusat data dan informasi Kementerian Kesehatan RI, 1-2. www.depkes.go.id/download.php?file $=\mathrm{d}$ ownload/.../infodatin lansia 2016.pdf\%0A

Nurfitri, R., Budiharto, I., \& Yulanda, N. A. (2019). Pengaruh Senam Ergonomik Terhadap Perubahan Tekanan Darah Lansia dengan Hipertensi. Proners, 4(1).

PDHI. (2019). Konsensus Penatalaksanaan Hipertensi. Indonesian Society Hipertensi Indonesia.

Perdana, R. M. (2014). Efektivitas Senam Ergonomik dengan Senam Aerobic Low Impact Terhadap Level Tekanan Darah Pada Lansia Hipertensi. Universitas Muhammadiyah Surakarta.

PERNEFRI. (2019). Hari Hipertensi Sedunia: Berantas Mitos Hipertensi. Swara PERNEFRI.

http://swara.pernefri.org/2019/05/harihipertensi-sedunia-berantas-mitoshipertensi/

Priyanti, K. (2016). Pengaruh Senam
Untuk peneliti selanjutnya diharapkan sebelum akan melakukan penelitian sudah memiliki rencana tempat apa yang digunakan yang dapat digunakan oleh laki-laki dan perempuan. Diharapkan untuk penelitian selanjutnya dapat memberikan intervensi senam ergonomik ini kepada penyakit lainnya seperti asam urat, kolesterol, stroke dan lainlain.

Ergonomik Secara Kelompok Dan Individu Terhadap Penurunan Tekanan Darah Pada Lansia Dengan Hipertensi Di Kelurahan Gisikdrono Semarang. Jurnal Ilmu Keperawatan Dan Kebidanan, 4(3), 57-71.

http://marefateadyan.nashriyat.ir/node/15 0

Riskesdas. (2018). Laporan Nasional Riset Kesehatan Dasar 2018. In Badan Penelitian dan Pengembangan Kesehatan. Lembaga Penerbit Badan Penelitian dan Pengembangan Kesehatan (LPB).

http://labdata.litbang.kemkes.go.id/imag es/download/laporan/RKD/2018/Lapora n_Nasional_RKD2018_FINAL.pdf

Sandi, H. (2017). Pengaruh Senam Tera Terhadap Penurunan Tekanan Darah Pada Lansia Dengan Hipertensi di Panti Sosial Tresna Werdha Nirwana Puri Samarinda. Universitas Muhammadiyah Kalimantan Timur, 9. https://paperless.umkt.ac.id/mahasiswa/d etail_metadata/241/

Suwanti, S., Purwaningsih, P., \& Setyoningrum, U. (2019). Pengaruh Senam Ergonomik Terhadap Tekanan Darah Lansia dengan Hipertensi. Jurnal Penelitian Perawat Profesional, 1(1), 112. https://doi.org/10.37287/jppp.v1i1.15 Wratsongko, M. (2015). Mukjizat gerakan shalat \& rahasia 13 unsur manusia. Mizania, 165. https://books.google.com/books/about/M 
Fakultas Keperawatan Universitas Klabat Bekerjasama dengan PPNI Provinsi Sulawesi Utara 